\title{
Response of Pollen Viability in Gladiolus (Gladiolus grandiflorus L.) to Storage Method and Period
}

\author{
Simarjit Kaur* and K.K. Dhatt \\ Department of Floriculture, Punjab Agricultural University, \\ Ludhiana (141004), Punjab, India \\ *Corresponding author
}

\section{A B S T R A C T}

\section{Keywords}

Gladiolus grandiflorus, Pollen storage, Viability, Desiccator, Freezer

Article Info

Accepted:

12 January 2019

Available Online:

10 February 2019

The experiment was conducted in Punjab Agricultural University, Ludhiana, Punjab during the season of 2016 and 2017 , in order to determine the pollen viability response to storage method and period in Gladiolus (Gladiolus grandiflorus L.). Gladiolus var. Yellow stone used as male parent for pollen collection. The corms of gladiolus were planted during October-December to obtained fresh pollen for research. Pollen grains of variety Yellow stone packed in plastic vials were stored in desiccator at ambient temperature, desiccator with $\mathrm{CaCl}_{2}$ at ambient temperature, desiccator under refrigerator, desiccator with $\mathrm{CaCl}_{2}$ under refrigerator $\left(5^{\circ} \mathrm{C}\right)$, lower cabin under refrigerator $\left(5^{\circ} \mathrm{C}\right)$, freezer $\left(-4^{\circ} \mathrm{C}\right)$ for 16 weeks from January to April. Pollen stored under different storage methods was used for determination of pollen viability. Maximum pollen viability was recorded under freezer i.e. $82.87 \%$. Pollen stored under freezer retained pollen viability for longer duration and it was recorded $85.09 \%$ after 11 weeks and pollen viability decreases to $49.58 \%$ after 16 weeks of storage. Pollen of the gladiolus can be stored for longer duration under freezer condition up to 11 weeks of storage without any serious loss of viability. The pollen of gladiolus can be stored in freezer $\left(-4^{\circ} \mathrm{C}\right)$ up to $2 \frac{1}{2}$ month for obtaining good pollen viability.

\section{Introduction}

Gladiolus is an important bulbous flowering plant and being used as cut flower in domestic and international market due to its brilliant floret. It belongs to family Iridaceae and subfamily Ixioideae, having approximately 150 known species (Negi et al., 1982). Most of the species are originated from tropical and South Africa and some from Mediterranean region (Jindal 1968). Basic chromosome number $\mathrm{n}=15$ and ploidy level from diploid
$(2 \mathrm{n}=30)$ decaploid $2 \mathrm{n}=12 \mathrm{x}=180$ (Lewis et al., 1972).

In gladiolus after first opening of flower, stigma remains receptive for pollination for up to three nights before senescing. Gladiolus is cross pollinated crop due to selfincompatibility (Johnson et al., 2009). For development of new varieties breeder go for crossing by hand pollination with fresh and stored pollen. The possibility of maintenance of pollen viability through the conservation 
process depends on factors such as flower physiological stage, storage temperature and relative humidity and moisture content in pollen (Akihama et al., 1979, Soares et al., 2008). Field conditions and relative humidity at the time of harvest affect the pollen moisture content, and germination ability, when pollen was kept for longer period of time in wet or high-humidity conditions (Hoekstra 1986).

Pollen viability in gladiolus is significantly reduced after $24 \mathrm{~h}$ of anthesis, approaching zero after 2 days. Long-term storage of pollen in gladiolus is necessary to facilitate crossing between spring-flowering species and summer-flowering species. Pollen germination of Lilium davidi var. unicolor and Gladiolus $\times$ hybridus after storage at $-80^{\circ} \mathrm{C}$ and $4^{\circ} \mathrm{C}$ were studied in relation to the changes in the carbohydrate content. With higher sucrose, glucose and fructose contents, L. davidi pollen showed higher germination than Gladiolus $\times$ hybridus pollen and maintained higher germination rate during storage. The total sugar content of both species preserved at $-80^{\circ} \mathrm{C}$ was higher than those preserved at $4^{\circ} \mathrm{C}$ and the pollen grains maintained their viability for longer period at $-80^{\circ} \mathrm{C}$ than at $4^{\circ} \mathrm{C}$ (Geng et al., 2013). Pollen of Gladiolus $\times$ gandavensis Van Houtte stored at $-80^{\circ} \mathrm{C}$ followed by storage at $0^{\circ} \mathrm{C}$ was suitable for long storage and the pollen viability declined fastest at $4^{\circ} \mathrm{C}$ (Geng et al., 2011).

As gladiolus is self-incompatible crop, flowers are emasculated manually one day before anthesis and pollinated in the early morning hours using fresh pollen. But sometime it is necessary to pollinate the flowers later and required to send the pollen to other place for seed production. Storage of pollen and its use in artificial pollination become more relevant, when the pollen have to be used in crossing and when the varieties bloom at different times. Efficient pollen storage method would also be helpful in transport pollen from one place to another during lean period. Therefore keeping these things in mind present investigation was carried out on storage of gladiolus pollen to determine pollen longevity of gladiolus under different storage conditions.

\section{Materials and Methods}

The present investigations research entitled "Response of pollen viability in gladiolus (Gladiolus grandiflorus L.) to storage method and period" were carried out at Department of Floriculture and Landscaping, Punjab Agricultural University, Ludhiana during 2016-17.

\section{Planting of variety yellow stone}

Corms of gladiolus were treated with Bavistin $0.2 \%$ against fungal diseases.

The treated corms were dried under shade after that planting was done at $30 \times 20 \mathrm{~cm}$ in well prepared beds. Planting of corms of Yellow Stone was done during October December to obtained fresh pollen and pollen for storage.

The experiment was conducted in Factorial Completely Randomized Design (FCRD) with three replications.

\section{Collection of pollen}

The flowers were tied with thread at the bud stage to obtain pure samples.

The flowers were harvested and brought to the laboratory. Petals were carefully separated and pollen grains were collected from the fresh flowers of variety 'Yellow stone' (male parent) by using forceps and needle, in plastic vials. 


\section{Pollen storage}

Pollen was stored for 16 week (January-April, 2017) with different storage methods i.e. Ambient temperature, Ambient temperature using $\mathrm{CaCl}_{2}$ in desiccators, Desiccators in refrigerator $\left(5^{\circ} \mathrm{C}\right)$, Desiccators in refrigerator with $\mathrm{CaCl}_{2}\left(5^{\circ} \mathrm{C}\right)$, Refrigerator in lower cabin $\left(5^{\circ} \mathrm{C}\right)$, Freezer $\left(-4^{\circ} \mathrm{C}\right)$ and Control (fresh pollen).

\section{Pollen viability test}

Pollen viability was checked at weekly interval from first week of January to last week of April. Pollen grains were placed on slides and then one drop of acetocarmine was placed on the grain. Cover slip placed over the slide and then observed under Leica Bright Field Research Microscope fitted with digital camera and computer imaging system using software NIS Element F3.0 at minimum of ten sites on slide from all the treatment at weekly interval from January 2017 to April 2017. Chromosome of viable pollen got stained with dye, acetocarmine while those of the other remain unstained. Stained pollen grain were counted .Viability was expressed as percentage of the pollen viability.

Pollen viability percentage $(\%)=$

$\frac{\text { No. of viable pollen }}{\text { Total no. of pollen }} \times 100$

\section{Statistical analysis}

The statistical analysis of the data as Factorial Randomized Block Design (FRBD), Factorial Complete Randomized Design (FCRD) and Randomized Block Design (RBD) by using CPCSI software developed by Department of Mathematics and statistics, PAU, Ludhiana.

\section{Results and Discussion}

In gladiolus pollen remains viable for a very short period after flower anthesis. Data obtained from this study showed significant difference in pollen viability under different treatments. Pollen viability of stored pollen was checked by acetocarmine dye which showed that pollen viability was significantly decreased after 3 weeks under ambient temperature. Meanwhile Desiccators in refrigerator $\left(5^{\circ} \mathrm{C}\right)$, Desiccators in refrigerator with $\mathrm{CaCl}_{2}\left(5^{\circ} \mathrm{C}\right)$, Refrigerator in lower cabin $\left(5^{\circ} \mathrm{C}\right)$ had significantly the highest pollen viability (\%) but not significantly higher than frozen pollen. Maximum pollen viability was recorded after first week of storage (89.53\%). The results (Table 1) indicate that pollen viability after second (89.38\%) and third $(89.18 \%)$ week of storage was also at par with that the mean value of first week. Pollen viability decreased as the storage period increased. The results showed that mean value of pollen viability at the end of storage period i.e. after 16 week of storage was $20.47 \%$.

The results of storage treatment showed that maximum for pollen viability was recorded in freezer $(82.87 \%)$ followed by desiccators containing $\mathrm{CaCl}_{2}$ under refrigerator $(55.75 \%)$. The pollen viability of fresh pollen was $97.03 \%$ and the minimum was in desiccators under ambient temperature (34.38\%).

The results of interaction between storage period and storage method with respect to pollen viability were significant. It indicate that the pollen storage in freezer help to prolong pollen viability for longer duration as compare to other methods of pollen storage. Maximum pollen viability was recorded in freezer $(99.86 \%)$ after one week of storage. The results of interaction also show that pollen storage in freezer maintained up to $90 \%$ pollen viability by $9^{\text {th }}$ week. It was closely followed by $99.74 \%$ freezer after two weeks of storage. The present study indicate that freezer $\left(-4^{\circ} \mathrm{C}\right)$ can maintain the pollen viability of gladiolus more than $95.00 \%$ after $8^{\text {th }}$ week and maintain $50.00 \%$ viability after $15^{\text {th }}$ week of storage (Fig. 1 and 2). 
Table.1 Effect of pollen storage period and methods on pollen viability (\%) of gladiolus variety 'Yellow Stone'

\begin{tabular}{|c|c|c|c|c|c|c|c|c|}
\hline \multirow{3}{*}{$\begin{array}{c}\text { Storage Period } \\
\text { Week }\end{array}$} & \multicolumn{8}{|c|}{ Storage methods } \\
\hline & \multicolumn{2}{|c|}{ Ambient temperature } & \multicolumn{3}{|c|}{ Refrigerator $\left(5^{\circ} \mathrm{C}\right)$} & \multirow{2}{*}{$\begin{array}{c}\text { Freezer } \\
\left(-4^{\circ} \mathrm{C}\right)\end{array}$} & \multirow[t]{2}{*}{ Control (fresh pollen) } & \multirow[t]{2}{*}{ Mean } \\
\hline & Desiccator & Desiccator with $\mathrm{CaCl}_{2}$ & Desiccator & Desiccator with $\mathrm{CaCl}_{2}$ & Lower cabin & & & \\
\hline $1^{\text {st }}$ & 82.22 & 83.94 & 86.27 & 88.25 & 86.40 & 99.86 & 99.78 & 89.53 \\
\hline $2^{\text {nd }}$ & 81.92 & 83.77 & 86.20 & 88.10 & 86.20 & 99.74 & 99.74 & 89.38 \\
\hline $3^{\text {rd }}$ & 81.77 & 83.54 & 85.87 & 87.97 & 86.13 & 99.39 & 99.64 & 89.18 \\
\hline $4^{\text {th }}$ & 77.05 & 81.47 & 84.38 & 87.19 & 85.10 & 99.53 & 99.25 & 87.71 \\
\hline $5^{\text {th }}$ & 71.25 & 75.83 & 82.96 & 86.12 & 81.73 & 98.32 & 99.12 & 85.05 \\
\hline $6^{\text {th }}$ & 62.86 & 68.26 & 77.47 & 85.32 & 73.35 & 97.44 & 98.19 & 80.41 \\
\hline $7^{\text {th }}$ & 57.06 & 62.58 & 69.58 & 79.91 & 68.65 & 96.23 & 97.69 & 75.96 \\
\hline $8^{\text {th }}$ & 30.41 & 56.56 & 57.38 & 74.89 & 64.76 & 95.36 & 97.16 & 68.07 \\
\hline $9^{\text {th }}$ & 5.33 & 27.25 & 46.59 & 66.79 & 58.64 & 89.95 & 96.77 & 55.90 \\
\hline $10^{\text {th }}$ & 0.00 & 16.50 & 40.68 & 59.55 & 44.74 & 85.32 & 96.57 & 49.05 \\
\hline $11^{\text {th }}$ & 0.00 & 0.00 & 31.17 & 43.85 & 39.08 & 85.09 & 96.34 & 42.22 \\
\hline $12^{\text {th }}$ & 0.00 & 0.00 & 21.87 & 27.86 & 25.00 & 66.96 & 95.75 & 33.92 \\
\hline $13^{\text {th }}$ & 0.00 & 0.00 & 13.35 & 16.29 & 18.99 & 59.57 & 94.82 & 29.00 \\
\hline $14^{\text {th }}$ & 0.00 & 0.00 & 0.00 & 0.00 & 0.00 & 53.07 & 94.02 & 21.01 \\
\hline $15^{\text {th }}$ & 0.00 & 0.00 & 0.00 & 0.00 & 0.00 & 50.65 & 93.93 & 20.65 \\
\hline $16^{\text {th }}$ & 0.00 & 0.00 & 0.00 & 0.00 & 0.00 & 49.58 & 93.73 & 20.47 \\
\hline Mean & 34.38 & 39.98 & 48.98 & 55.75 & 51.17 & 82.87 & 97.03 & \\
\hline
\end{tabular}

$\mathrm{CD}(0.05)$ Storage method $=0.27$

$\mathrm{CD}(0.05)$ Storage period $=0.40$

$\mathrm{CD}(0.05)$ Storage method $\mathrm{x}$ storage period $=1.07$ 
Fig.1 Effect of pollen storage methods on pollen viability (\%)

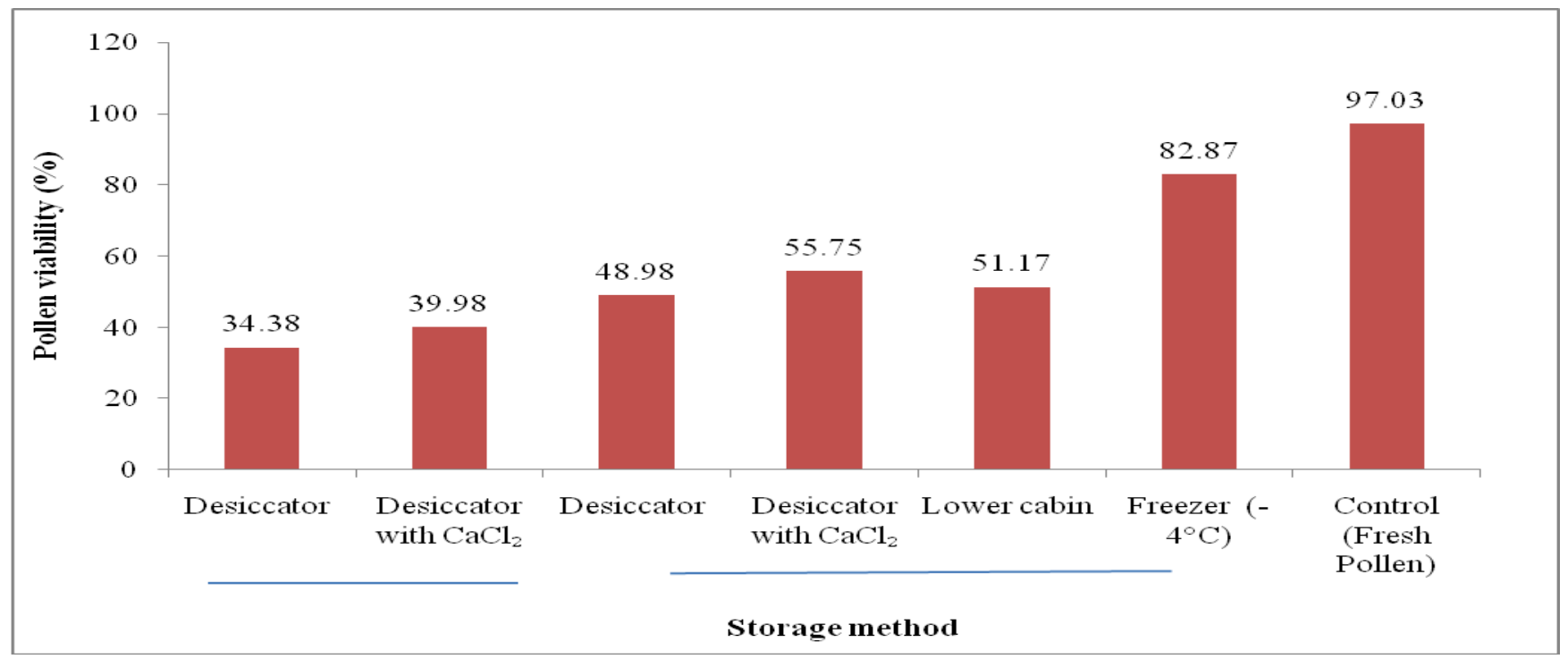

Fig.2 Effect of pollen storage period on pollen viability (\%)
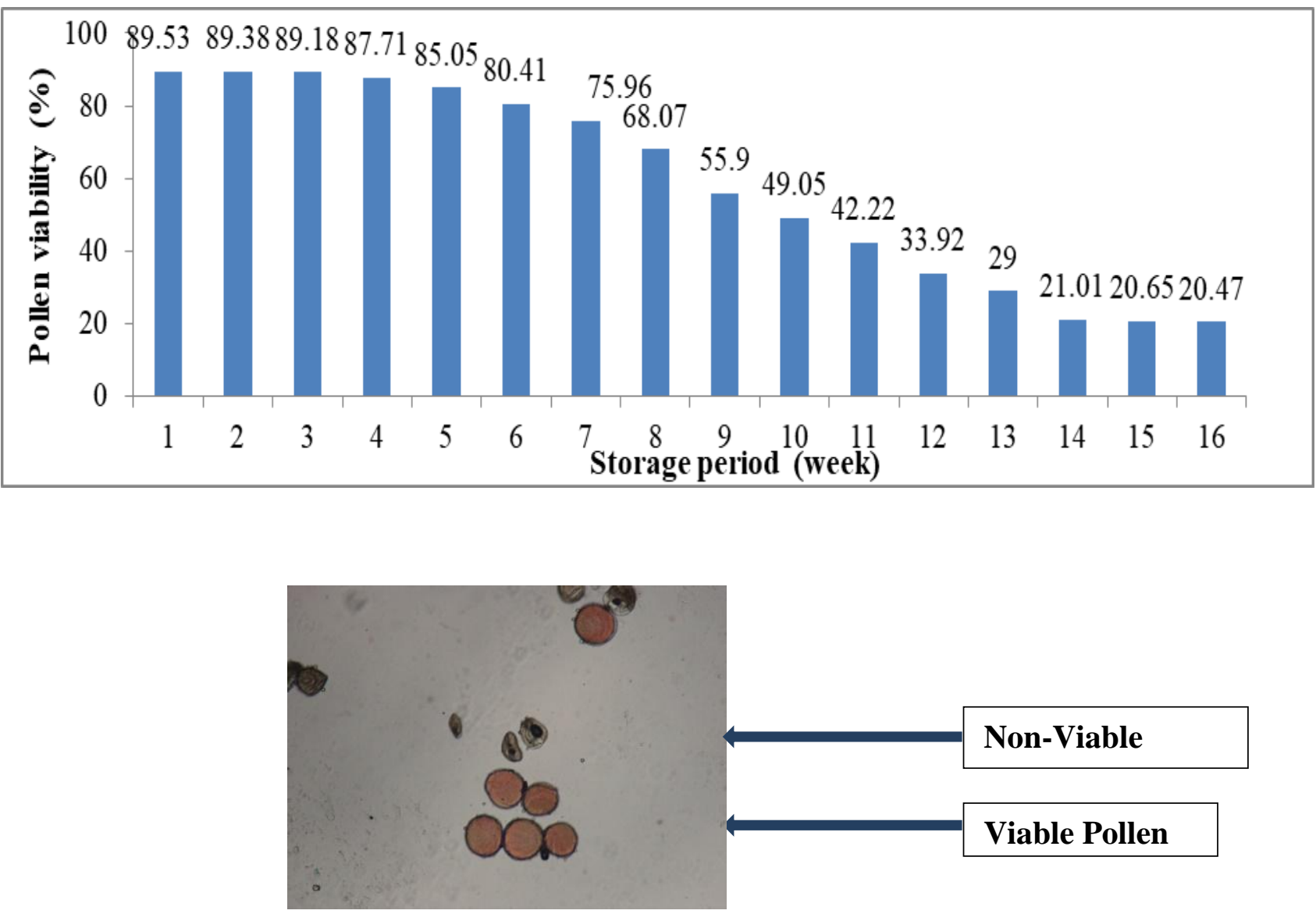
The second best method was desiccator with $\mathrm{CaCl}_{2}$ under refrigerator which maintains $85.32 \%$ pollen viability after 6 week of storage. Long term cryogenic storage of gladiolus pollen was recommended by Rajesekharan et al., (1994). Takastu et al., (2005) reported maximum pollen viability in gladiolus up to 2 month of storage.

The highest pollen viability till $9^{\text {th }}$ week in present study was recorded under freezer ($\left.4^{\circ} \mathrm{C}\right)$ storage. Koopowitz et al., (1984) and Barnabas and Kovacs (1997) studied that pollen of gladiolus was stored for longer period up to 2 year at low temperature. Wenli et al., (2009) also reported that pollen viability in Pingy in rose under frozen conditions decreased at slow rate and still retained highest pollen viability after 60 days and in some cultivars retained viability after one year. Yasumasa et al., (2001) studied the effect of storage temperature on pollen viability in gladiolus. They found that pollen of gladiolus can be stored at $-20{ }^{\circ} \mathrm{C}$ for one year.

From this present study, maximum pollen viability was recorded after first week of storage period $(89.53 \%)$. It decreased as the storage period increased. Pollen viability recorded at the end of storage period i.e. after 16 week of storage was $20.47 \%$. Under different storage methods, the pollen viability in freezer $\left(-4^{\circ} \mathrm{C}\right)$ was higher as compared to other storage conditions throughout the storage period. Pollen viability was recorded $99.00 \%$ during first four weeks in freezer ($\left.4^{\circ} \mathrm{C}\right)$.

The pollen viability of fresh pollen was $97.03 \%$ and the minimum viability was recorded in desiccator under ambient temperature i.e. $34.38 \%$. Hence we can say that pollen stored in freezer $\left(-4^{\circ} \mathrm{C}\right)$ have more pollen viability for long period as compare other storage method.

\section{Acknowledgement}

The authors thank Punjab Agriculture University for providing all the facilities to perform the study.

\section{References}

Akihama T, Omura M, Kosaki I (1979) Longterm of fruit tree pollen and its application in breeding. Tropical Agricultural Research, 13: 238-241

Barnabas B and Kovacs G (1997) Storage of pollen pp. 293-314.Shivanna K R, Sawhney V K (Edrs.) Pollen Biotechnology for Crop Production and Improvement. Cambridge University Press, Cambridge, U.K.

Geng X M, Huang B L, Luo F X, Wu Z H and Qiu J Y (2011) A study on cryopreservation of Gladiolus pollen. Journal of Nanjing Forestry University 35: 7-12.

Geng X, Qiu J and Okubo H (2013) Changes of carbohydrate content during Lilium and Gladiolus pollen cryopreservation. Grana, 52(3): 202-06.

Hoekstra F A (1986) Water content in relation to stress in pollen, $\mathrm{p} p$. 102-22. In Membranes, Metabolism and Dry Organisms (Eds. Leopold AC).Cornell University Press, Ithaca, New York.

Koopowitz, Voss H R and Omeik (1984) Long term storage of gladiolus pollen. Hort. Science, 19: 513-514.

Lewis G J, Obermeyer A A and Barnard T T (1972) Gladiolus: A revision of the South African species. Journal of South African Botany, 10:316.

Jindal S L (1968) Ornamental Bulbous Plants. Indian Council of Agricultural Research, New Delhi.

Johnson S D, Harris F and Proches S (2009) Pollination and breeding systems of selected wildflowers in a southern African grassland community. South 
African Journal of Botany, 75: 630-645. Negi S S, Sharma T V R S, Raghava S P S and Srinivasan V R (1982). Variability studies in gladiolus. Indian Journal of Horticulture, 39: 269-272.

Rajasekharan P E, Rao T M, Janakiram T and Ganeshan S (1994) Freeze preservation of gladiolus pollen. Euphytica, 80:105109.

Soares T.L., Silva S.O., Costa M.A.P.C, Santos-Serejo J.A., Souza A.S., Lino L.S.M., Souza E.H. and Jesus O.N. (2008). In vitro germination and viability of pollen grains of banana diploids. Crop Breeding and Applied Biotechnology, 8: 111-118.

Takatsu Y, Sukuki K, Yamada T, Inoue E,
Gonai T, Nogi $\mathrm{M}$ and Kasumi $\mathrm{M}$ (2005). Interspecific hybridization of wild Gladiolus species using a dendrogram based on RAPD analysis. Acta Horticulturae, 673: 475-480.

Yasumasa T, Kasumi M, Manabe $\mathrm{T}$ and Hayashi M (2001). Temperature effect on interspecific hybridization between Gladiolus grandiflora and $G$. tristis. Hort. Science, 36: 341-343.

Wenli W, Yong Z L, Ying Z C, Shu Z C, Peng Z Y and Fang G C (2009). Studies on pollen viability and its storage conditions of Pingyin rose. Actahorticulturae Sinica, 36(4): 593598.

\section{How to cite this article:}

Simarjit Kaur and Dhatt, K.K. 2019. Response of Pollen Viability in Gladiolus (Gladiolus grandiflorus L.) to Storage Method and Period. Int.J.Curr.Microbiol.App.Sci. 8(02): 16251631. doi: https://doi.org/10.20546/ijcmas.2019.802.191 